\title{
Design Process of a Campus Plan: A Case Study of Duzce University Konuralp Campus
}

\author{
Ozgur Yerli*, Sinem Ozdede** \\ *(Department of Landscape Architecture, Faculty of Forestry, Duzce University, Turkey \\ Email: ozguryerli@gmail.com) \\ ** (Department of Landscape Architecture, Faculty of Forestry, Duzce University, Turkey \\ Email: sinemozdede@hotmail.com)
}

\begin{abstract}
Humanity have always felt the need to alter the environment they inhabit. In our modern era, this desire continues to exhibit itself in more urban landscapes. As a microcosm of the cityscape, university campuses contribute many cultural and economic advantages to the urban population. Moreover they bring under control to the urban growth and generally provides open and green spaces to the city. In this paper, Düzce University Konuralp Campus, located north of the Düzce City, was considered as our study area. Here we describe the Konuralp campus design which was developed in "Duzce University Konuralp Campus Development Plan Urban Design Competition". The method of the study consist of three steps. Some analyses like location, topography (ecological wind corridors and the meeting point of the valleys), spatial zoning, design axes and circulation were performed at the first step. In the second step it has been tried to specify how to apply the steps for designing kind of these campus projects. The concept of the design was created and constructed for the project. In the last step the design was visualized with 3D aplications and presented here. The aim of the study is how to design a campus which is sustainable and accessible. Consequently, the campus design was realized which had some design principles based on pedestrian priority. Educational buildings were separated from social buildings, sports center and cultural centers by using a-pedestrian walkways. In the middle of the working area campus square was designed which contains some land uses such as ceremony area, student center, amphitheatre and library. Finally a sustainable and accessible campus design was developed for Duzce University.
\end{abstract}

Keywords: Campus, Design, Duzce, Sustainability, Visualize

\section{INTRODUCTION}

The word "campus" was first used in Princeton in the second half of the $18^{\text {th }}$ century in the United States and defined as the distance between college area and university buildings. Nowadays, the campus is being defined as to include all open \& closed spaces and open \& green spaces within the boundaries of the university [1]. The residential areas of the universities are called "campus". Campuses are areas where the educational activities are carried out, while at the same time there are also places providing opportunities for the students to improve their social and cultural developments and to benefit from the behaviour and communication skills inside the community [2].

Open spaces whether formal or informal are essential places to accommodate the life of campus community with its various outdoor activities [3]. In order to have a self-sufficient structure in university campus; apart from the educational structures, there should be other areas such as health, central administration, socio-cultural centers, libraries, sports center and areas, research and development center, accommodation, shopping center, support units and outdoor areas should be included [4].
In term of campus planning, stated that there are three aspects that should be emphasized; accessibility, safety and social engagement. In addition, this planning approach also provide various advantages in other aspect such as circulation, transportation, provision of facilities and other related aspects [5]. Ertekin and Corbaci (2010) also pointed out that the natural landscaping elements such as topographic structure, climate, etc. can also be said to be long-lasting and sustainable designs in the campus planning and design phases [6].

University campuses as centers of progression and innovation need to be sustainable. This is to enhance the community socially, environmentally and economically for teaching, and learning. The physical form of a place or campus could play a significant role, where there is limited research relating form to the sustainability. The access to open spaces and recreational areas is one of the principal components of campus sustainability. It refers to campus layout and locating green spaces on it contributing to create a walkable environment on campus [3].

According to Dober (1992) Landscape represents a skeleton for an outdoor environment of 
a campus [3]. He attributed the benefits of landscape as aesthetic, functional and climatological purposes. Aesthetic includes features such as artworks and sculptures. The functional purpose includes noise control, privacy and reducing erosion; while the climatic benefits include shade and air circulation.

Matloob at all. (2014) concluded that campus landscape features are about creating a sense of comfort and welcoming, better way finding, attractive scenery, and better safety. According to studies; there are four major aspects of landscape design on campus claimed to associate with campus sustainability;

-ease of movement

-sense of identity

-quality of public realm

-accessibility [3]

Every one of these aspects involve several design components that make up, together, the campus landscape character. From a socialpsychological perspective urban nature is an important component of quality of life for urban residents. Researchers have generally focused on benefits gained from "nearby nature", often measured as proximity to or amount of green space, or even a window view [7].

According to Altinsoy (2011), due to the growing population in Turkey, the university education requirements of citizens increased [8]. In order to compensate these needs, the government tended to establish new universities spreading them to whole country by introducing at least one university for each province. More-over, at the metropolitan provinces, multiple universities were installed which were followed by the private universities where possible. Introducing such number of universities required the construction of campuses that would serve physical and mental wellbeing of users including students, academic and administrative staff, and labors [9].

The physical organization and recreational opportunities of the university campuses play a particular role on the wellbeing of the students [10, $11,12]$. Additional this the campuses can be defined as open and green spaces in urban areas. Urban green spaces contribute positive impacts on the wellbeing of their users [13]. Many researches have been published on the landscape planning and design strategies for university campuses of Turkey $[6,14$, $15,16]$.

In this paper it was described the Konuralp campus design which was developed in "Duzce University Konuralp Campus Development Plan Urban Design Competition". The aim of the study is how to design a campus which is sustainable and accessible.

\section{MATERIAL AND METHOD}

Duzce city is located in Turkey's western Black Sea region and Duzce University is located north of the city Duzce. The main material of the study is Duzce University Campus. The campus is called "Konuralp Campus" which has about 180 hectares area. In campus there are 12 faculties, 3 institutes, a research hospital, sports center, social activity buildings and a recreation forest. The location of Duzce and Duzce University area was shown at Fig. 1.

The Duzce City Development Plan and campus master plan was used as material in the study. Satellite photos, study area photos, some computer programs like Autodesk AutoCAD, 3D StudioMAX and Adobe Photoshop were utilized for the creation of various images and visualization.

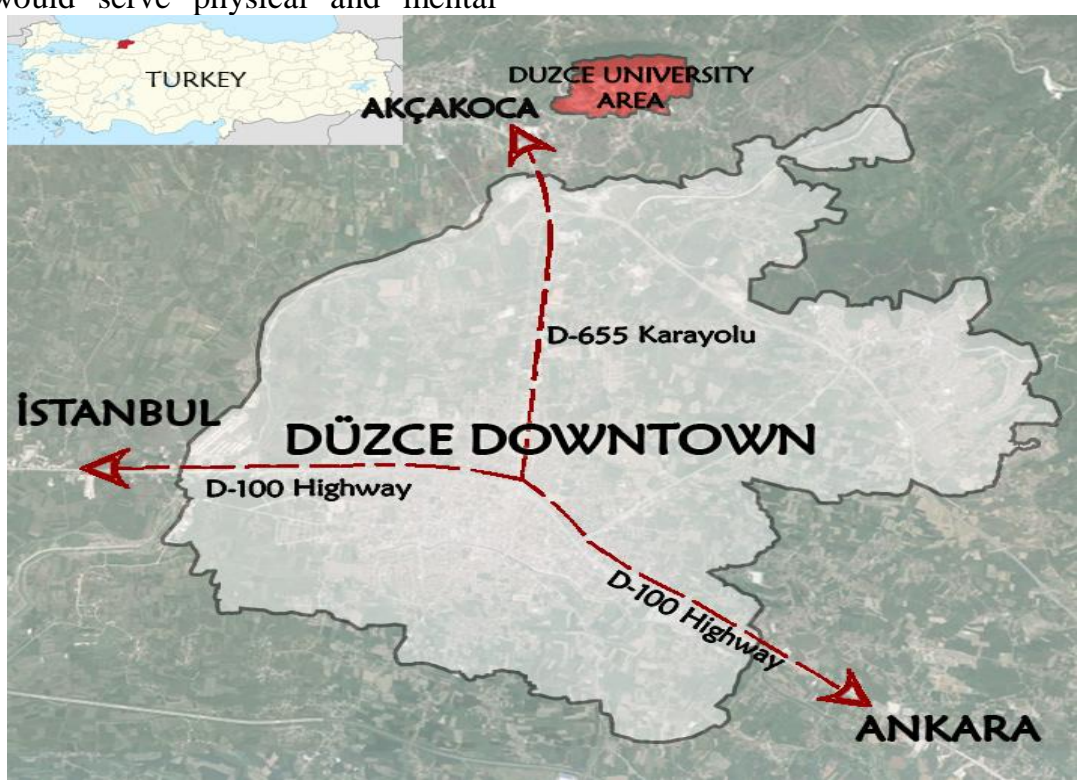

Figure 1. The location of Duzce and Duzce University area. 
The method of the study has consisted of the design process. At the first step the data like maps, pictures, natural and cultural information that belongs to the study area was collected. The obtained data were evaluated taking into account the current situation of the study area. After this step the collected data were analyzed and the necessity program was created. The basic of the concept and the design of the campus were constructed step by step.

\section{RESULTS}

\subsection{Ecological Wind Corridor and Meeting} Valleys

The two existing valleys (study area) in present topography of campus were utilized as significant ecological corridors. One of these valleys which is located between Faculty of Technical Education and Faculty of Science and Letters is proposed to be utilized as botanic valley and the other valley which is located between faculty of forestry and hospital is proposed to be utilized as valley of health - therapy forest. The valleys was shown at Fig. 2.

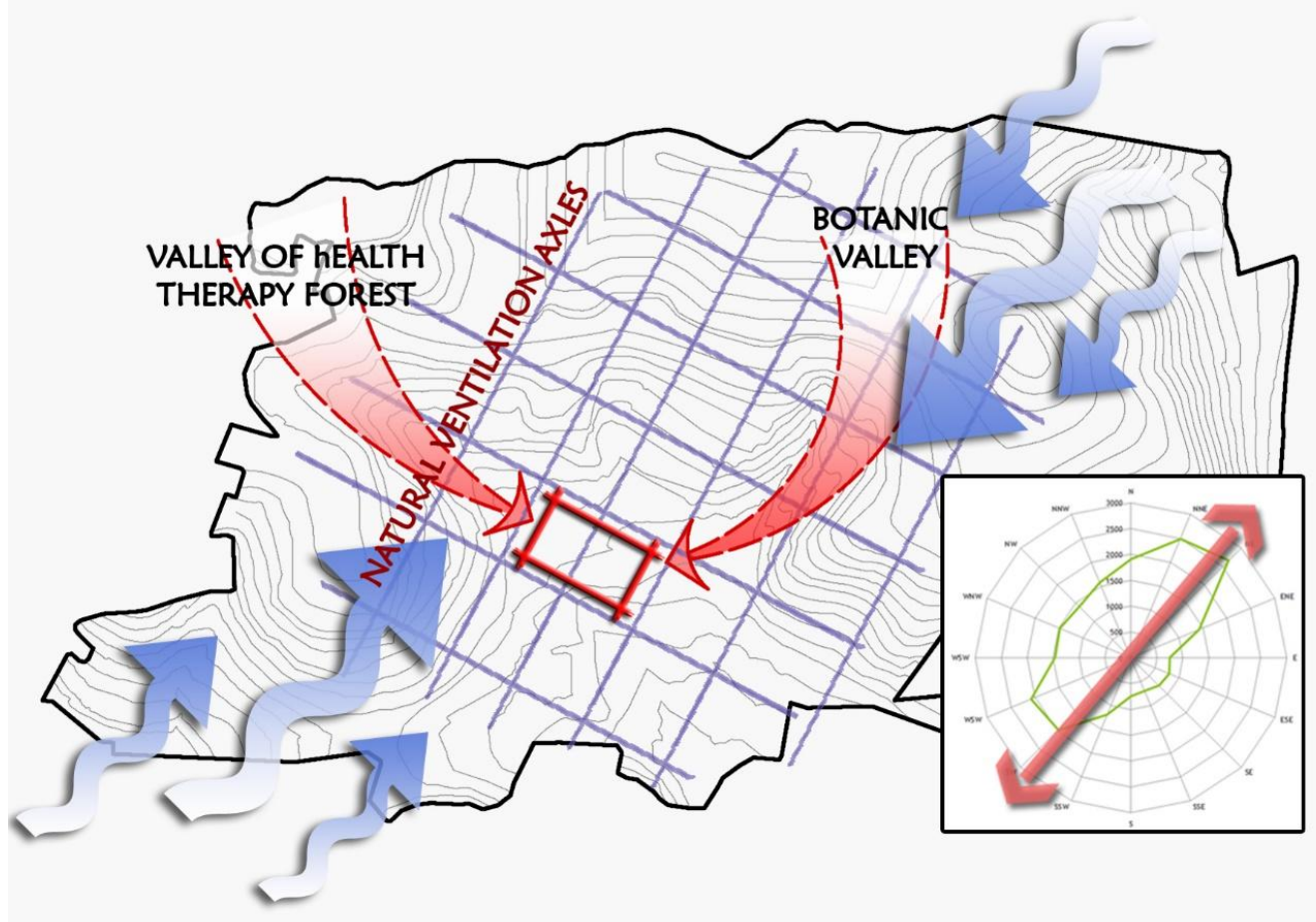

Figure 2. The two existing valleys in Duzce University area.

Both of the valleys have potentials to be wind corridors, this should be preserved and taken into consideration. The intersection area of these valleys is a very important center that is surrounded with education, health and sport units. Thus this area is virtually the hearth of campus. Above mentioned characteristics of this area exhibit the positional specifications clearly in terms of locational setup. In Düzce town dominant wind direction is in the direction of north-east south-west. The proposed axles shall provide ecological contribution since they are in the same direction with natural ventilation axels. Similarly Lau et al. (2014) emphasized that natural ventilation contribute has made many positive contributions to the landscape and the building which located in that landscape [17].

\subsection{Locational Zoning}

The utilized areas in the campus are evaluated under five titles. These are the followings; health units (hospital and other related units), education units (faculties, classrooms, labs), social activity centers and sport units (amphitheatre, library, square, ceremonial ground, campus path, students center and sport complex), recreation forestry and forest. The locational zoning of the campus and the land uses was shown respectively at Fig. 3. and Fig. 4. It seems that as stated by Tolon [4] in order for university campuses to be selfsufficient, there should be other usable areas such as health, sports, library activities and outdoor use areas located in the study area. 


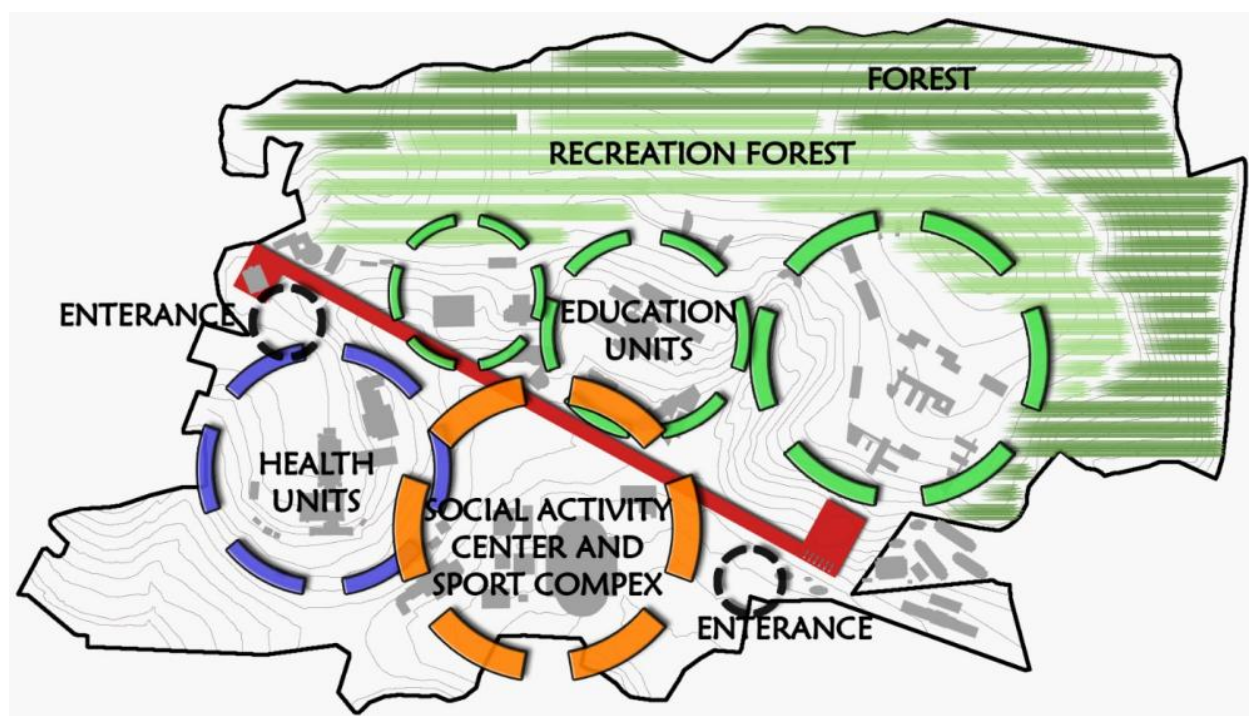

Figure 3. The locational zoning of the campus.

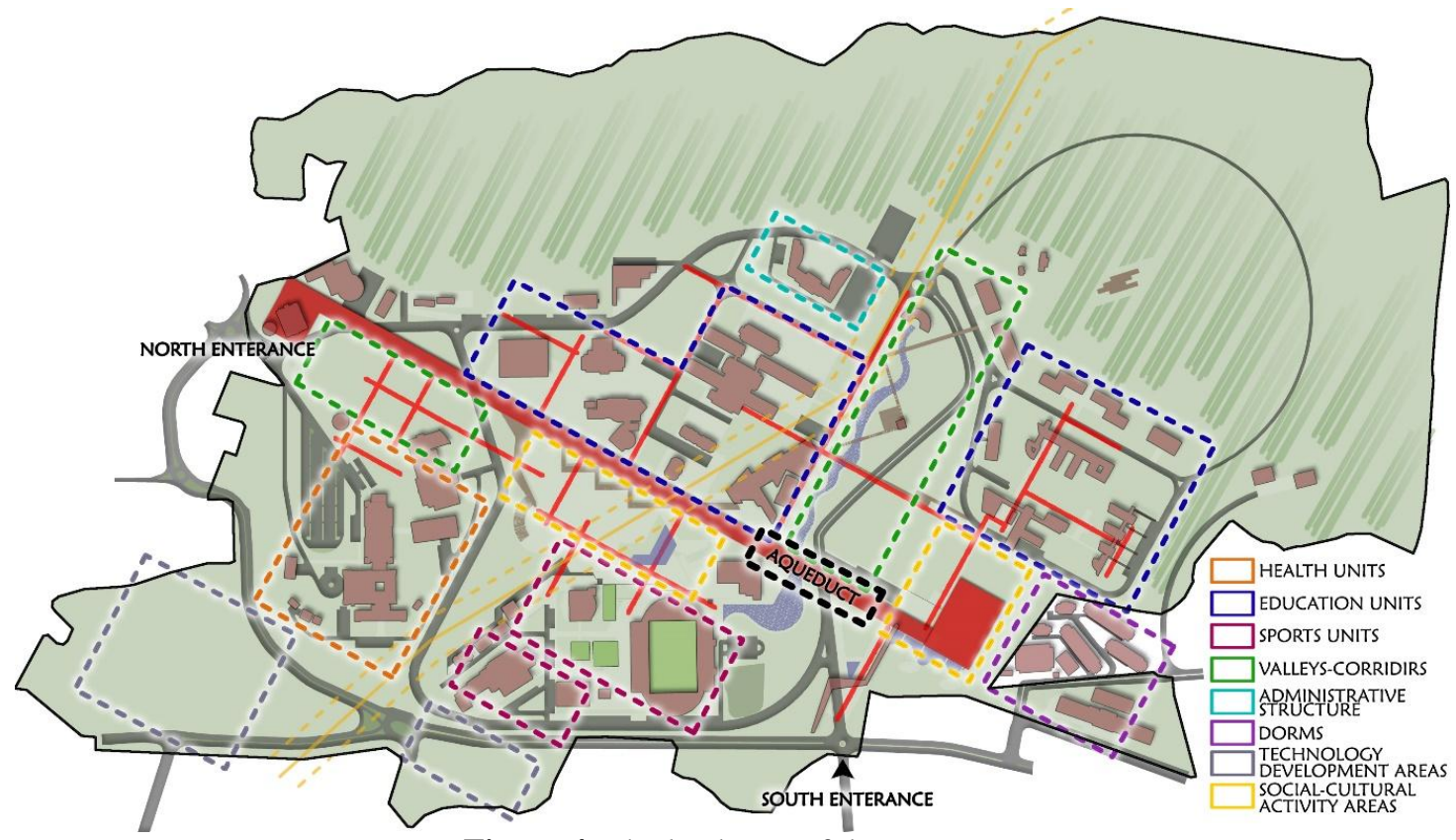

Figure 4. The land uses of the campus.

It is provided that all user groups have relations directly with main pedestrian axel (arched path). All the proposed education units are located on the north of arched path and square, students center, shops and library are located on the south of arched path.

\subsection{Design Axels}

The origin points which direct to design are the present positions of valley systems which are under protection and wind corridors and structural bodies. The orientations of these parameters have created base for axels and axels were integrated with main carrier spine (arched path). This spine became the main pedestrian axel due to its position (location) and functions. Closed, open and semi open locations are also created. The design axels was shown at Fig. 5 . 


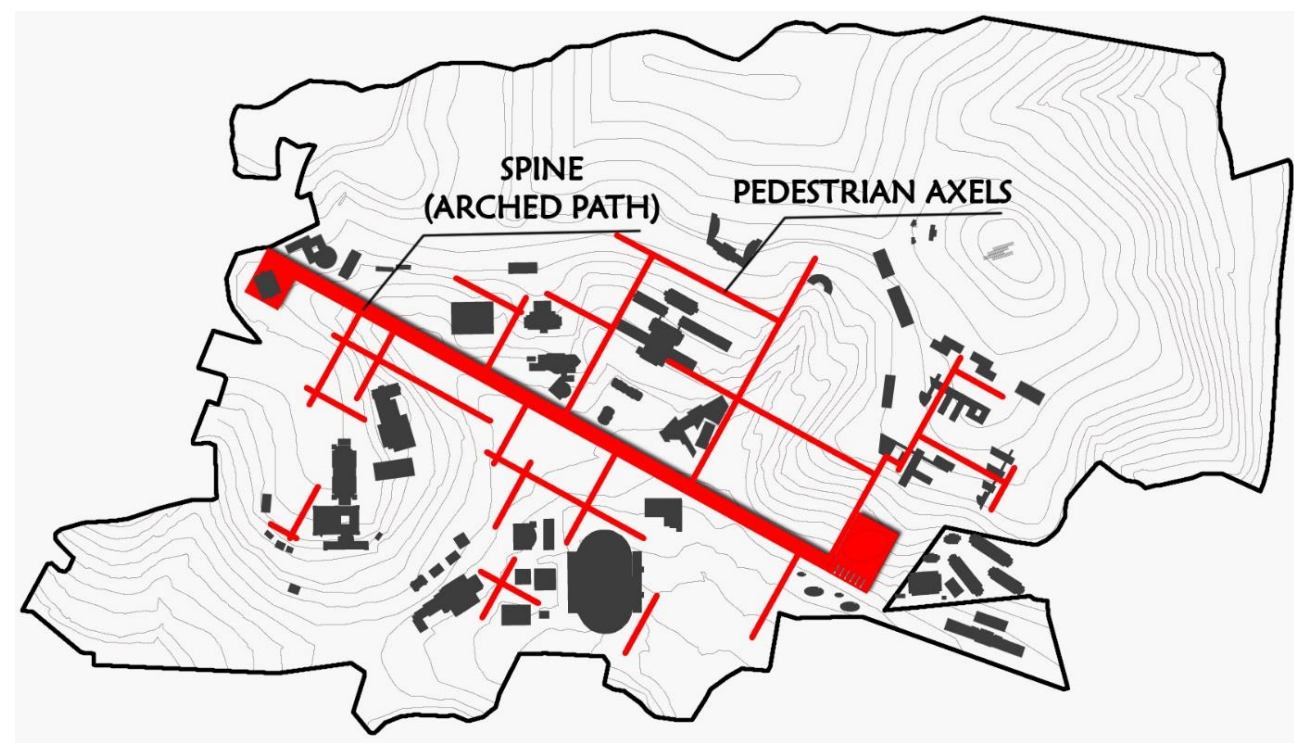

Figure 5. The design axels.

\subsection{Transportation}

The present entry on the south of campus area was protected and its construct was empowered. The basic origin in transportation creates a campus that has a dominant prior pedestrian transportation web. The transportation vehicles (car, bus, lorry, etc.) are blocked to enter the campus square and students' center. The faculties and other units are reached from their surroundings. For this purpose a ring fed by southern and western entries of campus is routed.

On the arched path where at vehicle and pedestrian traffics intersect, subways and overpass were designed. Thus pedestrian traffic is not prevented. On the other hand the accessibility of disabled, old people and children are supported. While determining the bus stop points for public transport the distance between bus stops are set 400 meter which is not more than five minutes on foot. The transportation idea was shown at Fig. 6.

\subsection{Concept}

Some researchers described the campuses as small cities $[18,19]$. However, they have their own physical characteristics that are different from cities or towns [3].

A researcher stated that landscape is a major factor in defining the campus experience. It embodies cultural as well as aesthetic values. Designers and planners are challenged with identifying the spaces that embody the essence of the campus, the "places of memory" that create emotional ties, and to preserve them for future generations. But the character of a campus is also defined by many less visible, and also highly valued spaces [20].

Matloob at all. (2014) stated that, in terms of the comfort when using walkways, design qualities included walkway width, the potential of walking away from street, paving quality, separating pavement from street by plants and the protection from weather effects were resulted as significant factors [3].

The origin point of design setup is the concern about planning the traffic by pedestrian paths. For this reason the priority of pedestrian was set as the main target. The capillary pedestrian path on vertical direction was integrated with arched path (horizontal main pedestrian axel). The arched path is 25 meters width and cuts the campus on the axis of northwest and southeast. It is a sustainable, living pedestrian area. The arched path starts from culture center and ends at the complex of the faculty of theology. It combines the culture center, education units, health bodies, sport complex and centers of art, business and social activity each other. The environmental design was created in the consideration that concerts and ceremonies would be held in this area. There are also open, closed and semi closed social activity areas for concerts, ceremonies and festivals. While the whole social activity center becomes a big scene during a concert, the arched path serves as balcony since it is higher than social activity center. The concept plan was shown at Fig. 7. and the general view of the campus was shown at Fig. 8. 


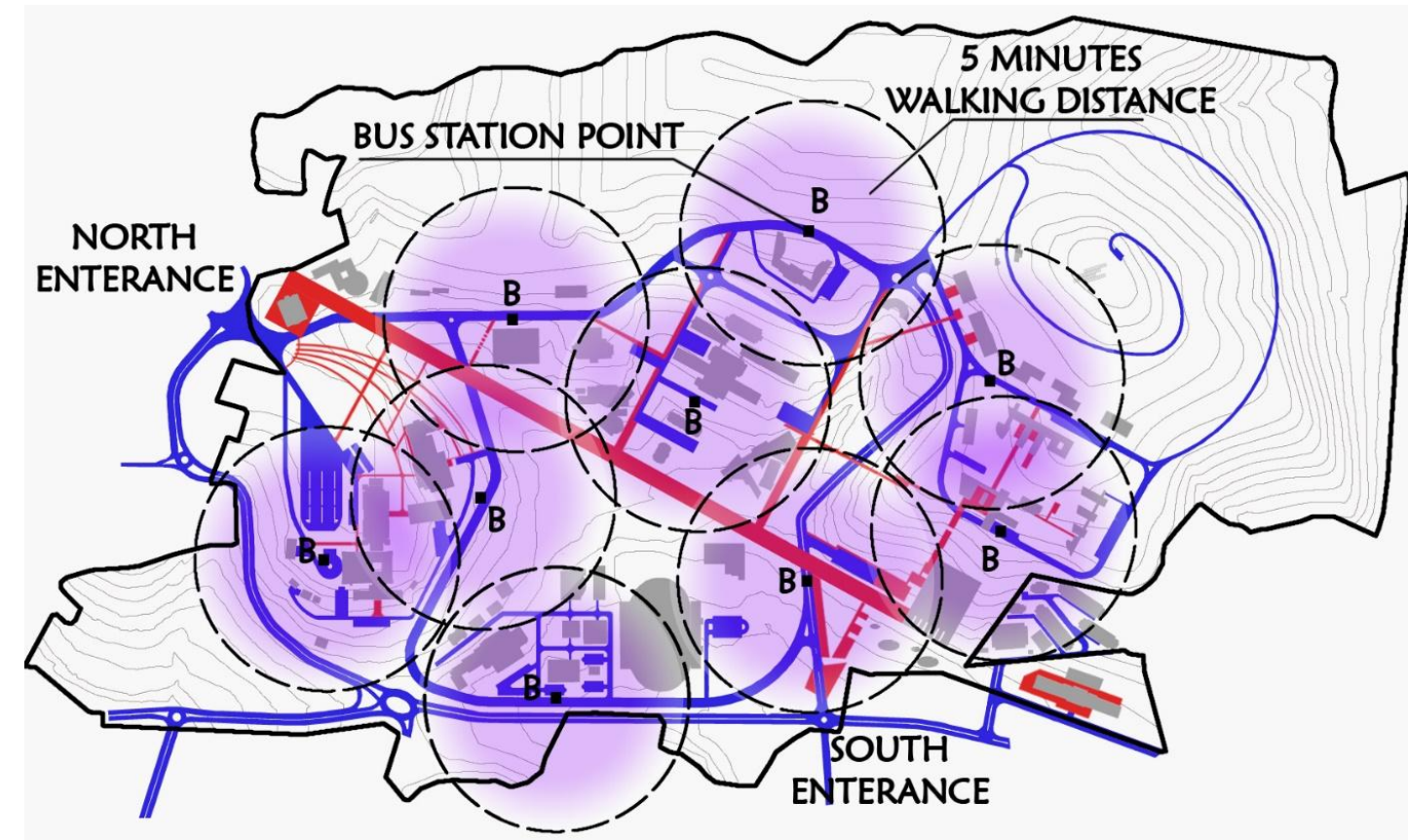

Figure 6. The transportation.

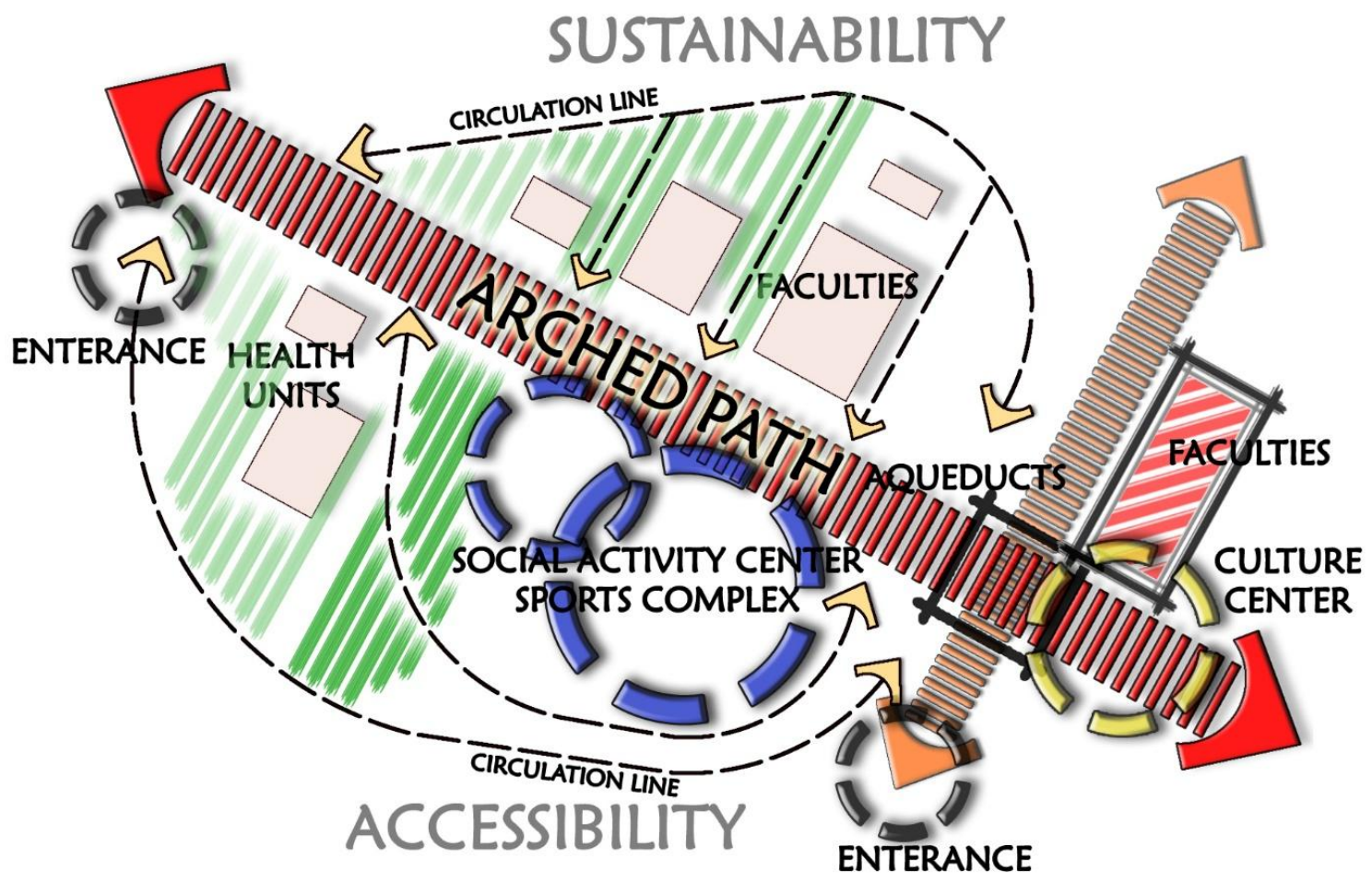

Figure 7. The concept plan.

One other factor that matures the design setup depends on the reinterpretation of cultural items and architectural values in the local geography. Historical items of Konuralp location was referred and water arches were crated at the end of botanic valley and pedestrian spin was created within the enlargement of water arches. The water arches attract the visitors visually at the entrance of the campus. The arched path and the other pedestrian axels were shown at Fig. 9. 


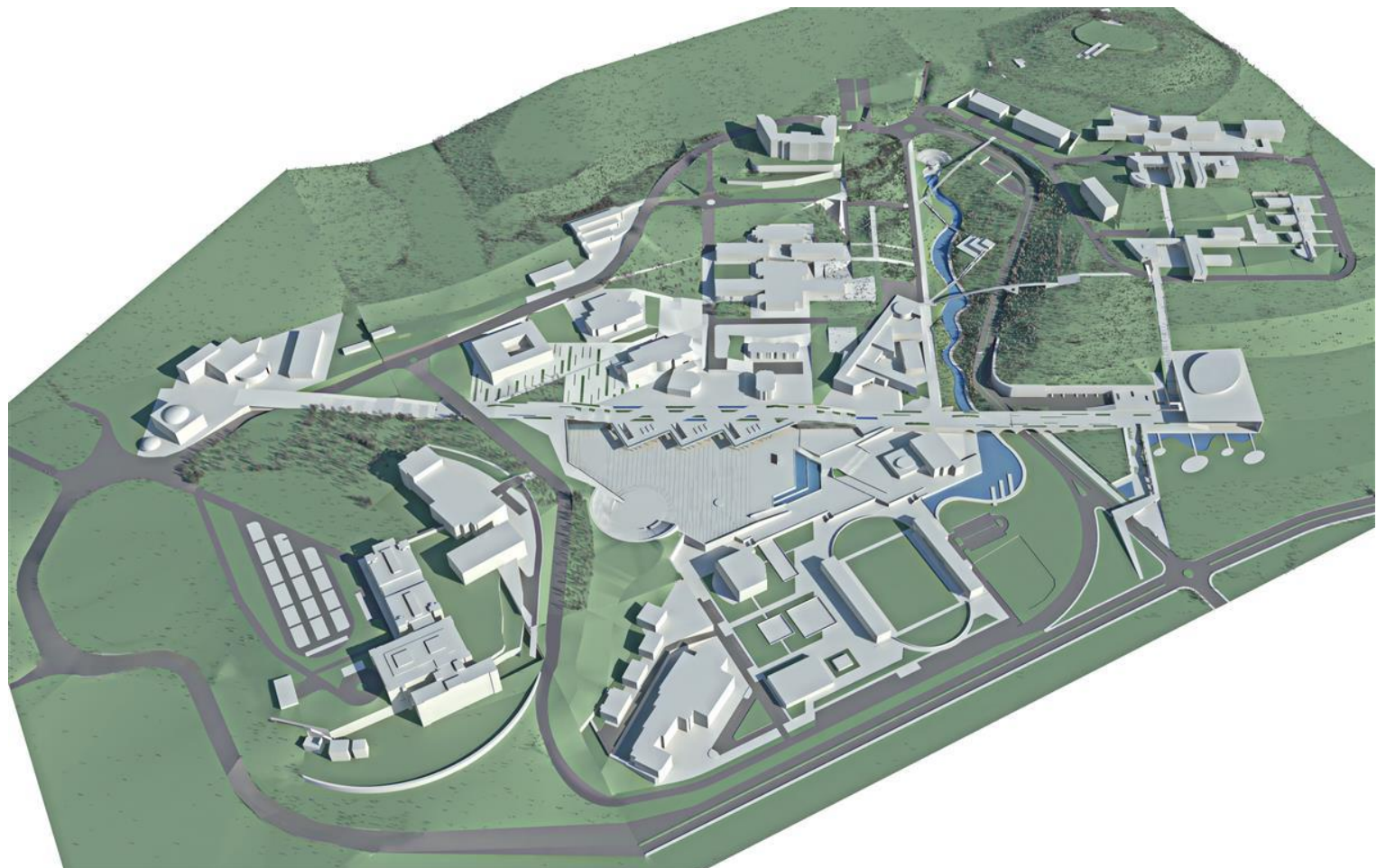

Figure 8. The general view of the campus.

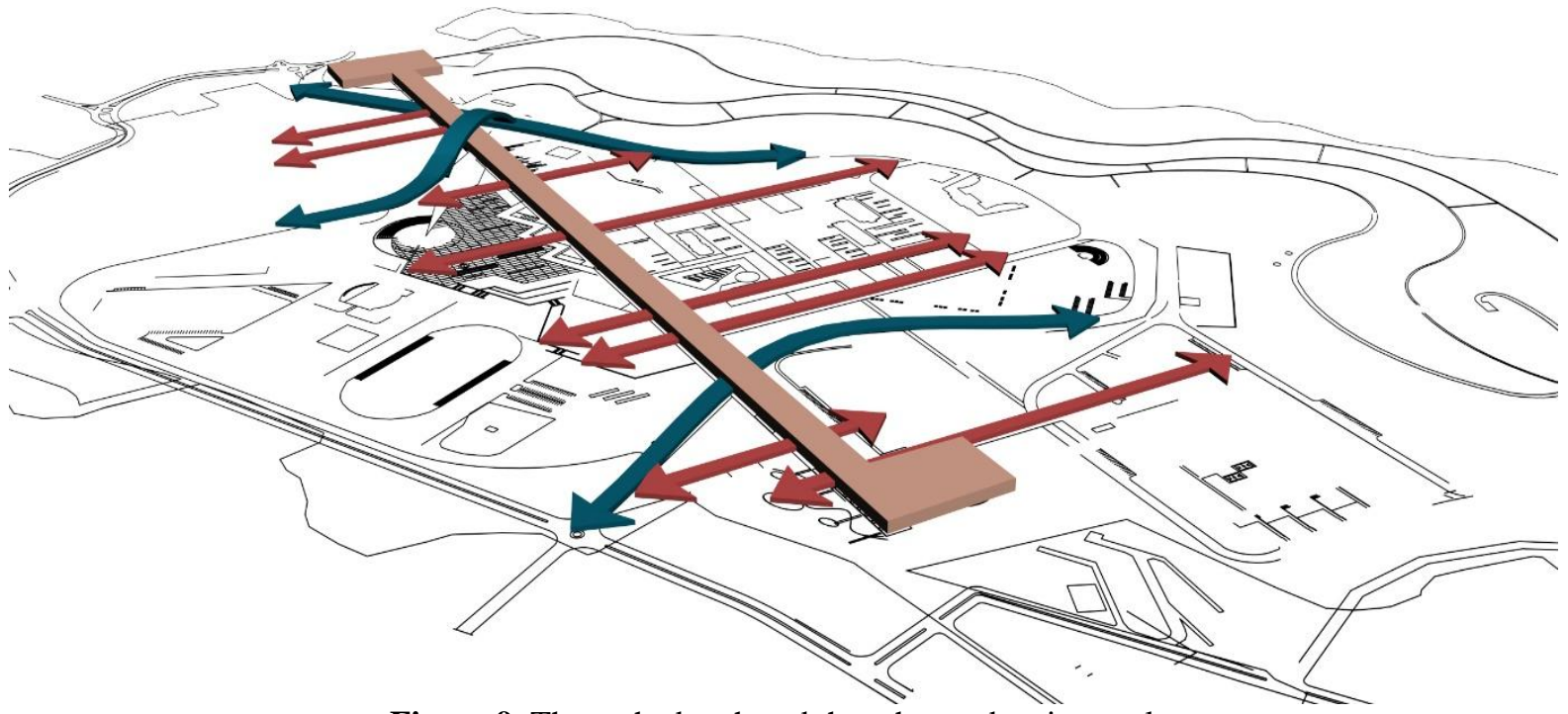

Figure 9. The arched path and the other pedestrian axels.

It also has functions such as providing water float and traffic for vehicles and pedestrians under itself as well. On the social activity square amphitheatre was designed. Innovative and sustainable approaches were exhibited on the new products in the light of modern art perspective rather than representing history. The arched path and the amphitheatre were shown at Fig. 10. The images of social activity and student center with the arched path were shown at Fig. 11. 


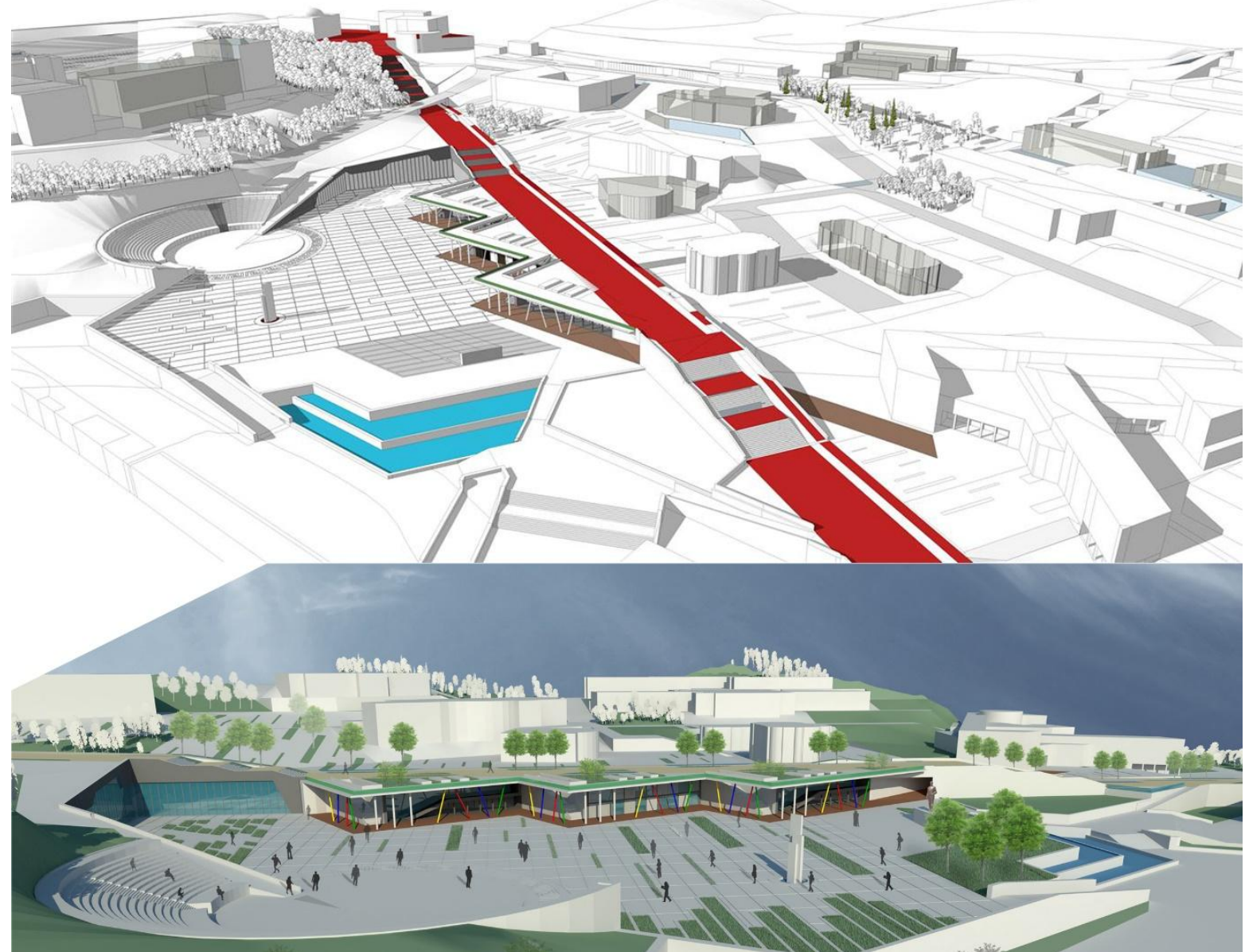

Figure 10. The arched path and the amphitheatre.
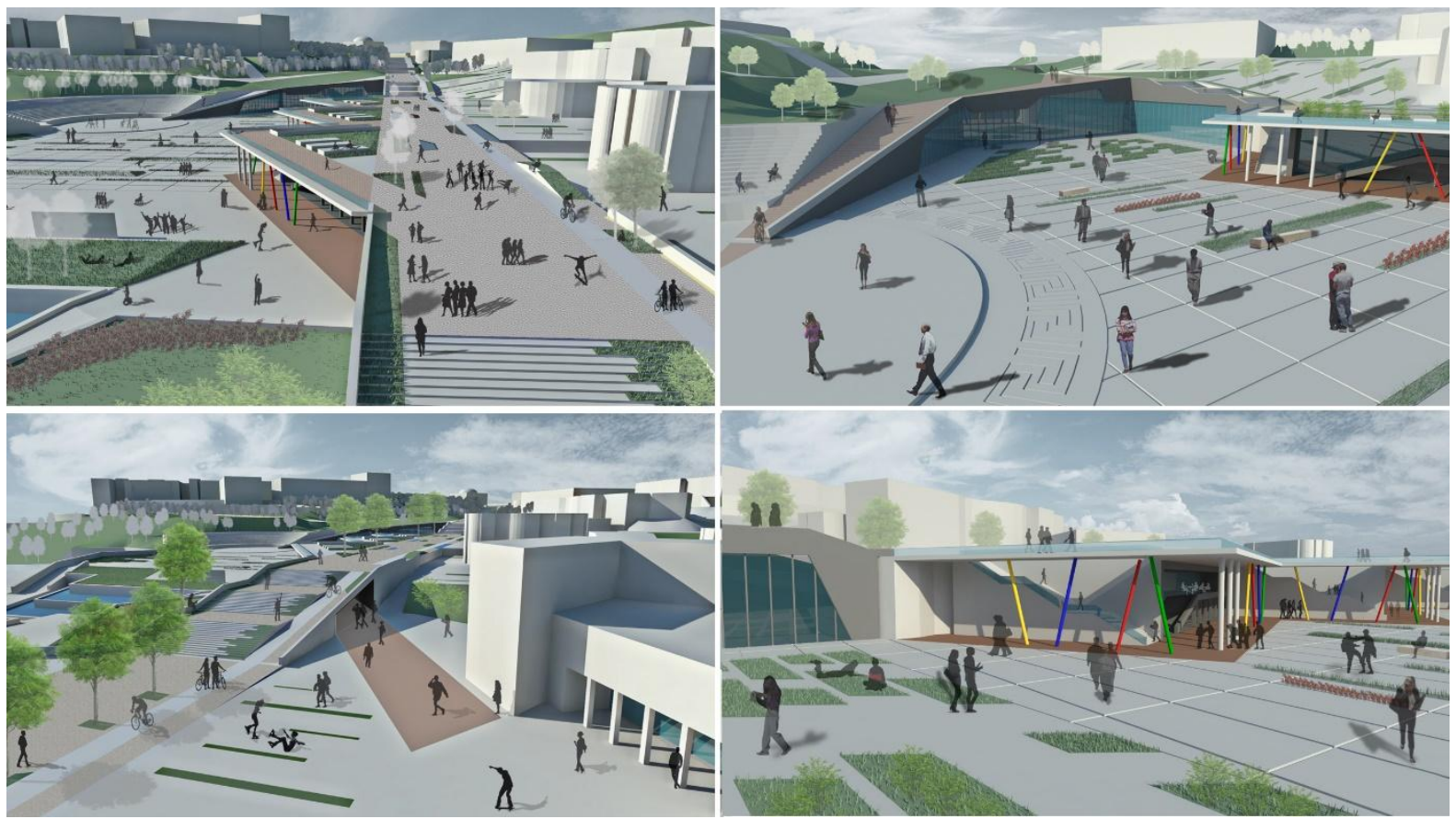

Figure 11. The images of social activity and student center with the arched path. 


\subsection{Recreation Forestry}

The recreation forestry is handled with protection of current forest pattern. The path ways for walking in the recreation forestry which is located on a sloping land also are also created in parallel to this slope and there are passes to each other in patches. Therefore it is possible to watch the campus in four seasons from different altitudes and vistas. There are also resting localities, paintball spaces proposed alternatively. The recreation forestry also provides opportunity to observe its natural beauties, flora and wild life. It is possible to reach the recreation forestry and terrace at the top from the present structures on the north of the campus as well. Recreation forestry and the all campus were shown at Fig. 12.

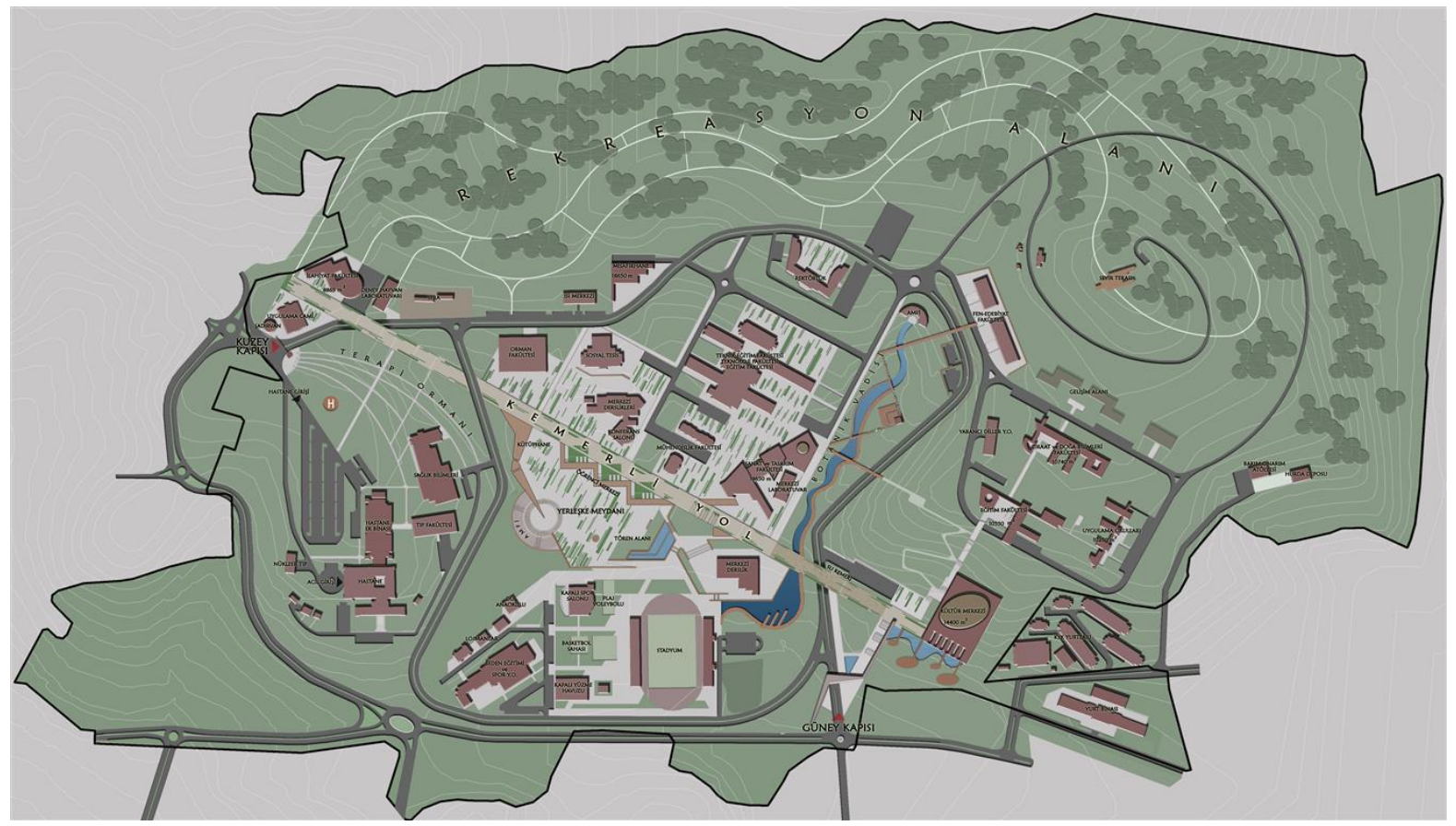

Figure 12. Recreation forestry and the all campus.

The outdoor spaces on campus support the relationships between people and increase the quality of university life [21, 22]. Tolon [4] mentioned that flora and fauna should be kept in mind while designing campus areas and stated that on-campus planting work should be done predominantly with the plants found in natural vegetation. Through the recreation forest, the quality of life on the university campus has been increased and a positive contribution has been made to the floral and fauna existence.

\section{CONCLUSION}

The campuses are an important component of open and green space systems and they contribute positively to the city they are found. Nevertheless the campuses include not only education areas, but also social spaces where social activities such as sports, culture and arts are performed. Therefore, it should be remembered that while the university campuses are designed, the priority factor is the pedesterians and all planned activities should be fed from the main pedestrian circulation as much as possible. Campus planning and designs should be accessible, holistic, sustainable and developable.

Consequently, in this paper the campus design was realized which had some design principles based on pedestrian priority. Education buildings were separated from social buildings, sports center and cultural center by using a pedestrian road. In the middle of the working area campus square was designed which contains some land uses like ceremony area, student center, amphitheatre, library. Finally a sustainable and accessible campus design was developed for Duzce University.

\section{REFERENCES}

[1] A. Gul, E. Keles, O. F. Uzun, Recreational Demand and Trends in the Campus Students and Lecturers of Süleyman Demirel University, Süleyman Demirel University Journal of Architecture Sciences and Applications, 1(1), 2016, 26-43.

[2] T. Yilmaz, D. Gokce, F. Savkli, S. Cesmeci, A Research on the Use of the Common Locations by the Disabled People within the University Campuses: An Example of the 
Olbia Culture Center of Akdeniz University, The Journal of Tekirdag Agricultural Faculty, 9(3), 2012, 1-10.

[3] F. A. Matloob, A. B. Sulaiman, T. H. Ali, S. Shamsuddin, W. N. Mardyya, Sustaining Campuses Through Physical Character-The Role of Landscape, Procedia Social and Behavioral Science, 140, 2014, 282-290.

[4] M. B. Tolon, University Campus Exterior Design Principles and Ankara University Golbasi Campus Landscape Design. Ankara University Graduate School of Natural and Applied, Unpublished Master Thesis, 2006.

[5] M. Z. Abd-Razak, N. K. F. Mustafa, A. I. Che-Ani, N. A. G. Abdullah, M. F. I. MohdNor, Campus Sustainability: Student's Perception on Campus Physical Development Planning in Malaysia, Procedia Engineering 20, 2011, 230 - 237.

[6] M. Ertekin, O. L. Corbaci, Landscape Planning at University Campuses (The Landscape Project Case Study of Karabük University), Kastamonu Univ., Journal of Forestry Faculty, 10 (1), 2010, 55-67.

[7] K. N. Irvine, R. A. Fuller, P. Devine-Wright, J. Tratalos, S. R. Payne, P. H. Warren, K. J. Lomas, K. J. Gaston, Ecological and Psychological Value of Urban Green Space, Dimensions of the Sustainable City. ISBN 978-1-4020-8646-5(HB), Springer, 2010.

[8] S. Altinsoy, Problems of Newly-Founded Universities and Solution Offers, Journal of Higher Education and Science, 1(2), 2011, 98-104.

[9] M. Ozturk, E. Gokyer, O. L. Corbaci, Evaluation Of Student Perception On Landscape Planning And Design Of University Campuses Around The Case Of Agdaci Campus, Bartin University, Turkey, Inonu University Journal of Art and Design, 6(13), 2016, 49-55.

[10] A. L. McFarland, T. M. Waliczek, J. M. Zajicek, The Relationship Between Student Use of Campus Green Spaces and Perceptions of Quality of Life. Hort Technology, 18(2), 2008, 232-238

[11] S. S. Y. Lau, F. Yang, Introducing Healing Gardens Into a Compact University Campus: Design Natural Space to Create Healthy and Sustainable Campuses, Landscape Research, 34(1), 2009, 55-81.

[12] J. A. Hipp, G. B. Gulwadi, S. Alves, S. Sequeira, The Rrelationship Between Perceived Greenness, Perceived Restorativeness of University Campuses and Student-Reported Quality of Life. Environment and Behavior, 2015, 1-17.
[13] G. Carrus, M. Scopelliti, R. Lafortezza, G. Colangelo, F. Ferrini, F. Salbitano, M. Agrimi, L. Luigi Portoghesi, P. Semenzato, G. Sanesi, Go Greener, Feel Better? The Positive Effects of Biodiversity on the WellBeing of Individuals Visiting Urban and Periurban Green Areas, Landscape and Urban Planning, 134, 2015, 221-228.

[14] A. B. Korkut, M. S. Cilek, Landscape Planning Principles of University Campuses, II. National Campus Planning and Environmental Organization Workshop, June 9-10, Kahramanmaras, Turkey, 2005.

[15] H. Turgut, P. Yesil, S. Yilmaz, Determining the Recreational Demands and Tendencies of Students at Ataturk University Through Questionnaires, Scientific Research and Essay, 4(3), 2009, 152-158.

[16] S. Yilmaz, Landscape Design of a Campus Outdoor Spaces: Suleyman Demirel University Faculty of Forestry Building, Kastamonu University Journal of Forestry Faculty, 15(2), 2015, 297-307.

[17] S. S. Y. Lau, Z. Gou, Y. Liu, Healthy Campus by Open Space Design: Approaches and Guidelines, Frontiers of Architectural Research, 3(4), 2014, 452-467.

[18] M. Z. Abd-Razak, N. A. Goh Abdullah,M. F. I. Mohd Nor, I. M. S. Usman, A. I. Che-Ani, Toward a Sustainable Campus: Comparison of the Physical Development Planning of Research University Campuses in Malaysia. Journal of Sustainable Development, 2011, 4(4), doi: 10.5539/jsd.v4n4p210

[19] H. M. Alshuwaikhat, I. Abubakar, An Integrated Approach to Achieving Campus Sustainability: Assessment of the Current Campus Environmental Management Practices, Journal of Cleaner Production, 16(16), 2008, 1777-1785. doi: 10.1016/j.jclepro.2007.12.002

[20] G. G. Hannah, Campus Planning \& Design: The Academic Landscape, A Report On Landscape Forms Leaders Roundtable. February 11-12, 2013, Arizona State University.

[21] M. Biddulph, Bringing Vitality to a Campus Environment, Urban Design International, 4(3), 1999, 153-166.

[22] D. Aydin, U. Ter, Outdoor Space Quality: Case Study Of A University Campus Plaza, Archnet-Ijar, 2(3), 2008, 189-203. 